\title{
América Latina ao extremo: relato a partir da cidade do México
}

América Latina al extremo: informe de la Ciudad de México

Latin America to the extreme: report from Mexico City

L'Amérique Latine à la limite : récit à partir du Mexique

Ana Luisa Senna, Karen Lisset Baltazar Herrera e Jhonatan Bento da Silva

\section{(2) OpenEdition}

Journals

\section{Edição electrónica}

URL: http://journals.openedition.org/espacoeconomia/12496

DOI: 10.4000/espacoeconomia.12496

ISSN: 2317-7837

\section{Editora}

Núcleo de Pesquisa Espaço \& Economia

Refêrencia eletrónica

Ana Luisa Senna, Karen Lisset Baltazar Herrera e Jhonatan Bento da Silva, « América Latina ao extremo: relato a partir da cidade do México », Espaço e Economia [Online], 18 | 2020, posto online no dia 20 abril 2020, consultado o 20 maio 2020. URL : http://journals.openedition.org/espacoeconomia/ 12496 ; DOI : https://doi.org/10.4000/espacoeconomia.12496

Este documento foi criado de forma automática no dia 20 maio 2020.

(c) NUPEE 


\title{
América Latina ao extremo: relato a partir da cidade do México
}

\author{
América Latina al extremo: informe de la Ciudad de México \\ Latin America to the extreme: report from Mexico City \\ L'Amérique Latine à la limite : récit à partir du Mexique
}

Ana Luisa Senna, Karen Lisset Baltazar Herrera e Jhonatan Bento da Silva

1 Sob a ótica da corrente realista, as relações internacionais se caracterizam através de uma visão pessimista no que tange os laços cooperativos, e seus historiadores partilham o pensamento de que um sistema anárquico favorece o egoísmo entre os Estados. Em meio ao cenário caótico da Guerra Fria (1947-1991), o neorrealista Kenneth Waltz lança seu livro em 1959 intitulado "O Homem, o Estado e a Guerra" (WALTZ, 1959), no qual é defendido pelo autor que os Estados atuam de acordo com o próprio interesse, e de que a guerra é uma ferramenta eficiente de poder coercitivo para o benefício dos Estados, que buscam sempre obter vantagens na então "balança de poder"; ou seja, o equilíbrio de poder em meio à um sistema anárquico. Em seu livro, Waltz se referia a guerra como uma ação bélica, no entanto, em meio à pandemia provocada pela disseminação em larga escala do Corona vírus, a disputa estatal por meios de controle e vantagem perante os outros Estados afim de proteger a si mesmo torna sua obra presente em pleno século XXI.

2 É evidente que, apesar da existência de instituições internacionais pacificadoras - como a Organização das Nações Unidas -, os Estados ainda buscam sua sobrevivência e agem conforme seus próprios interesses. Mas, diferentemente das guerras bélicas onde há o conflito direto, atualmente os "ataques" são realizados através da busca imprudente e inconsciente por vantagens individuais em meio a uma crise sanitária global, como têm feito os Estados Unidos, que o fizeram ser acusados de "pirataria moderna" ${ }^{1}$, por impedirem que suprimentos essenciais nesse momento de sensibilidade cheguem aos seus destinos ao reforçar seu padrão liberal recorrendo cinicamente à antiga lei da "oferta e da demanda". Fica a dúvida: estariam os Estados Unidos reafirmando seu imperialismo hegemônico através de "boicotes" sanitários em meio a uma epidemia, ou é um 
pouco desse nacionalismo exacerbado que está em falta nos países latino-americanos, que continuam deixando suas fronteiras abertas e sua população exposta com medo da estagnação econômica? Neste artigo, são dois estudantes brasileiros morando na cidade do México e uma mexicana a tentar responder tal questionamento².

Importante ressaltar que na América Latina e Caribe, até abril de 2020, o número de infectados pelo novo coronavírus já ultrapassou a casa dos 50 mil casos. No Brasil, cuja população é de 209,5 milhões de pessoas, 23.430 casos já foram registrados e 1.328 mortes já foram calculadas. No México, a população supera 126,2 milhões de pessoas, e são 4.661 casos e 296 mortes $^{3}$. O Brasil lidera o ranking de países na América Latina com o maior número de infectados, enquanto o México ocupa a terceira posição, atrás da Bolívia. Apesar de ambos Brasil e México contarem com um sistema de saúde pública, os números são extremamente alarmantes, superando a capacidade dos espaços de saúde. Há superlotação e os respiradores disponíveis nos dois países já não suprem a demanda, além dos números de testes serem insuficientes e gerarem subnotificações.

\section{O isolamento social na Cidade do México}

4 A Cidade do México é uma das cidades mais populosas do mundo. Seu ar é pesado para aqueles que não estão acostumados devido a mescla de altitude e contaminação. Mas em abril, o ar da cidade já não está mais tão intragável como estava em meio ao frio do inverno mexicano em janeiro. Nota-se que o ar está mais limpo, afinal, com a pandemia enfrentada a nível mundial, muitas pessoas estão fazendo suas atividades através de plataformas digitais.

5 Mas o céu não parece tão limpo para os vendedores autônomos. É possível ver o desespero no semblante desses vendedores, que juntos somam mais de 56 milhões de pessoas, representando 56,3\% da população total do México, segundo o jornal mexicano El Economista ${ }^{4}$. Apesar de ainda haver um grande fluxo de pessoas nas ruas, o movimento já não é mais o mesmo, o que impacta diretamente em suas economias. Todos estão, de forma justa, preocupados 5 .

6 Segundo uma pesquisa realizada em 2018 pelo Organisation for Economic Cooperation and Development (Organização de Cooperação Econômica e Desenvolvimento) ${ }^{6}$, os mexicanos são o povo que mais tem carga horária de trabalho por ano no mundo, superando as 2000 horas. Para piorar um pouco, o salário é recebido de acordo com o dia trabalhado. Ou seja: sem trabalho, sem dinheiro. Mas, qual é a relação entre o mercado laboral mexicano e o coronavírus? A maioria das pessoas que estão nas ruas são pessoas em situação de vulnerabilidade; caso não trabalhem, não terão dinheiro para comprar o próprio sustento. É uma escolha difícil, mas previsível: sair e correr o risco de ser contagiado e contagiar pessoas ou ficar em casa e não ter dinheiro para comer. Entre uma possibilidade e um fato, as pessoas acabam se arriscando. E como resultado, poucas pessoas estão, de fato, fazendo quarentena em casa.

7 A quarentena no México ainda não é obrigatória. Está no estágio dois, no qual não é permitido apenas lugares fechados com mais de 50 pessoas. Transitar nas ruas ainda é um exercício comum. As fronteiras ainda estão abertas para serviços essenciais, como por exemplo para as relações bilaterais de comércio (ou melhor dizendo, dependência) dos Estados Unidos e México. As crianças ainda brincam na rua. Mas as faculdades e empresas estão atuando através do "home office" (trabalho em casa). Um grupo está "protegido", enquanto o outro segue sua rotina buscando sua sobrevivência. 
Para estimular as pessoas a permanecerem em casa, criaram propagandas com o lema "Quedate em casa" ("Fique em casa"). A intenção é compreensível, mas ficar em casa sem trabalhar não é uma opção para todos, tornando a frase um pouco problemática devido a sua estrutura elitizada. Ficar em casa, em tais condições, infelizmente e tragicamente não é uma opção para todos. Infelizmente, para recebermos nossas comidas em aplicativos como "Uber Eats", "Sin Delantal" e "DiDi Food" no conforto e segurança de nossas casas, algumas pessoas precisam sair e ir trabalhar. O cenário é de angústia, principalmente entre os diversos estrangeiros que estão confinados no país sem saber quando poderão regressar para casa.

9 Mas, sair do México não é simples, e se o seu destino for o Brasil torna-se ainda mais complexo, já que o país apresenta números ainda mais alarmantes. Afinal, embora grande parte da população tente agir com sensatez respeitando as recomendações da Organização Mundial de Saúde (OMS) e as demais autoridades locais, muitos subestimam o potencial destrutivo do vírus e continuam fazendo suas atividades normalmente. Não somente as essenciais, mas também as dispensáveis e mundialmente repreendidas, como sair para passear ou ir na academia. Todos se preocupam, mas pouco é feito. $\mathrm{O}$ humor atua como uma válvula de escape nos meios digitais, mas o medo é real e constante. E, ironicamente, o que mais preocupa para quem está acompanhando as notícias no país são as falas do chefe de Estado brasileiro - aquele que foi eleito para solidificar a soberania nacional e proteger sua população, mas, que no momento, age de forma pejorativa perante às medidas de segurança.

10 A sensação de negligência à população e submissão perante a economia nunca foi tão forte nos dois países. É plausível dizer que uma crise nacional devido a estagnação econômica é factualmente grave. Mas, é absurdo não perceber que uma população dizimada por um vírus devido a negligência de líderes políticos e falta de políticas públicas direcionadas à população seja algo muito mais sério, e muito mais caótico. 0 isolamento nunca foi tão necessário, e concomitantemente, tão difícil.

\section{Os mais vulneráveis}

11 Tanto no Brasil, quanto no México, a desigualdade social é uma realidade expressa em índices alarmantemente maiores do que em países desenvolvidos. Isso significa que a falta de suporte científico somada a deficiência de aparatos tecnológicos para enfrentar a pandemia se agrava de maneira exorbitante entre os países latino-americanos. Para agravar um pouco mais a situação brasileira, os centros responsáveis pelo desenvolvimento e pela pesquisa nacional do país sofreram vários cortes do governo, tornando o Estado brasileiro um epicentro de desmonte educacional, científico e tecnológico, enfraquecendo ainda mais a sua população no combate à COVID-19, provocando o regresso do Brasil enquanto país geoestratégico no sistema internacional.

12 No México, devido ao histórico de incessantes corrupções políticas em meios televisivos, a população atualmente é desconfiada de qualquer tipo de informação oriunda de meios midiáticos, muitas vezes reagindo de maneira áspera a elas, sendo consequência da perda de credibilidade das televisoras locais devido ao seu partidarismo. Mesmo que menos atingidos por "fake news" como estratégia de líderes políticos, a descrença mexicana sobre toda e qualquer informação tem cegado seus habitantes perante à atual crise sanitária mundial, os expondo a graves riscos. 
13 Como resultado, temos todo um continente despreparado para enfrentar esse fenômeno que tem assolado todo o mundo e que invisibiliza as graves diferenças sociais existentes, como o caso das pessoas que habitam as favelas brasileiras e as tribos indígenas do México e Brasil. São áreas cada vez mais marginalizadas economicamente e esquecidas perante as políticas públicas das administrações governamentais. Os que mais sofrem são as populações carentes, que em sua maioria são afrodescendentes e indígenas, segundo o relatório "Afrodescendientes en Latinoamérica: hacia um marco de inclusión”, realizado pelo Banco Mundial em 2018².

14 Segundo a ONU-Habitat, "favelas" são espaços onde não há a presença dos serviços públicos básicos, como água, eletricidade e saneamento básico - condições essenciais para uma vida digna e saudável ${ }^{8}$. Esses espaços predominantemente ocupados pela população afrodescendente, principalmente no Brasil, são consequências vivas de uma história marcada pela colonização e precariedade para essa população, sendo um drama também presente na realidade dos indígenas. No México, a população indígena também se encontra em situação de vulnerabilidade, estando mais exposta que o restante do país devido a barreira linguística existente no país: o espanhol não é a língua oficial de algumas comunidades que possuem seu próprio idioma ${ }^{9}$. A falta de acessibilidade para essa população é, indiscutivelmente, uma falha do poder público mexicano vigente.

É importante ressaltar que esse cenário pode agravar ainda mais o risco das comunidades negras e indígenas, visando que tanto no México quanto no Brasil, o racismo ambiental, estrutural, cultural e institucional está presentes em sua rotina. A pandemia pode impulsionar ainda mais a marginalização dessas populações. Nesse panorama, a realidade em que vivemos é de uma política altamente letal, também conhecida como necropolítica ${ }^{10}$, que com o advento do capitalismo e das novas formas da ideia de "fazer morrer" ou "deixar morrer", as tecnologias de destruição evoluem e não dão importância aos corpos das vítimas letais, uma vez que estão mais preocupados com a evolução da ferramenta que será a causadora do "fazer morrer" e com o retorno econômico causado por esta evolução tecnológica.

\section{Considerações Finais}

Os relatos brasileiros e mexicanos em relação ao que tange o coronavírus são similares, com diferenças pontuais "adaptadas" de acordo com cada território, assim como seus interesses e necessidades.

17 No que se refere ao cotidiano dos estudantes, as aulas permanecem sendo ministradas através de plataformas online. Foi a maneira proporcionada pelas universidades locais, principalmente no México, para darem continuidade ao seu trabalho sem arriscarem os estudantes à exposição. No entanto, isso é problemático: as universidades brasileiras não adotaram até então essa medida pela consciência das dificuldades de grupos mais vulneráveis ao acesso remoto que possibilitaria o acompanhamento das atividades. Novamente, questões socioeconômicas vêm à tona.

Uma diferença considerável é em relação a postura dos presidentes dos dois países, já que o presidente mexicano se preocupa com a situação enquanto o presidente brasileiro trata a pandemia de forma pejorativa. Todavia, ambos têm menor protagonismo em relação ao combate da doença ao serem comparados com os governantes das unidades federativas - os governadores do Brasil e os "jefes de governo" 
mexicanos -, que vêm se destacando mais incisivamente na promoção dos cuidados de prevenção para a população.

Esse momento de sensibilidade expôs para o mundo as fragilidades de todos os países. Se a China, país em que se iniciou a propagação do vírus, atualmente apresenta dados mais positivos em relação à mortalidade e à quarentena, a América Latina sofre as consequências de ter tomado medidas insuficientes e, muitas vezes, negligentes perante o combate do vírus. A América Latina continua carregando as marcas da colonização e permanece submissa às vontades e necessidades americanas. Nota-se isto ao permitir suas fronteiras abertas e pela pauta da economia se sobressaindo sobre as necessidades da saúde. São necessárias medidas mais rigorosas de isolamento e medidas de auxílio econômico a todos os públicos, a fim de proteger a população de maneira plural, sem distinção de classe social ou empecilhos linguísticos. A balança de poder é, realmente, fluída. Enquanto a China - pertencente ao chamado BRICS, grupo de países emergentes que o Brasil faz parte - vem se fortificando principalmente devido aos seus avanços tecnológicos, o Brasil e a América Latina parecem continuar presos em uma colonização invisível e viciosa, já enraizada em sua história, mas desta vez, tendo como dominador o próprio criador da Doutrina Monroe ${ }^{11}$.

\section{BIBLIOGRAFIA}

Banco Mundial. Afrodescendentes na América Latina: Rumo a um Marco de Inclusão. Washington, DC: World Bank, 2018.

MBEMBE, Achille. Necropolítica. 3. ed. São Paulo: n-1 edições, 2018.

UN-Habitat, World Cities Report 2016. Urbanization and Development: Emerging Futures (Ke Findings and Messages), Nairobi: United Nations Human Settlements Programme, 2016.

WALTZ, Kenneth N. Man, the state, and war : a theoretical analysis. Séries: Topical studies in international relations. New York : Columbia University Press, 1959.

\section{NOTAS}

1. Ver: https://www.bbc.com/portuguese/internacional-52166245. Acesso em: 16 de abril de 2020.

2. Ana Luisa Senna, nascida em Minas Gerais, Brasil, e estudante de Relações Internacionais na Universidade Federal Rural do Rio de Janeiro (UFRRJ), localizada no município de Seropédica, Rio de Janeiro, estuda atualmente Negócios Internacionais na Universidad Nacional Autónoma de México, devido a uma bolsa de estudos da minha instituição de origem. Jhonatan Bento da Silva, também brasileiro e estudante de Relações Internacionais da UFRRJ, atualmente está em mobilidade acadêmica no curso de Ciências Políticas pela Universidad Autónoma de Tlaxcala, México. Karen Lisset Baltazar Herrera é mexicana e estudante de Contabilidade da Universidad Nacional Autónoma de México.

3. Foi consultado o portal: https://coronavirus.jhu.edu/map.html. 
4. Consultar: https://www.eleconomista.com.mx/empresas/Informalidad-repunta-a-56.3-de-lapoblacion-ocupada-20190925-0053.html. Acesso em: 16 de abril de 2020.

5. "Tamales, tamales, tamales salados, tamales dulces" é um grito comum às 7 horas da manhã na capital mexicana. Trata-se de um alimento a base de milho comum no café da manhã típico nas populosas ruas da capital mexicana. Mesmo em idade avançada, perceptível pela sua voz trêmula, e, portanto, pertencente ao grupo de risco, o trabalhador em questão permanece em sua rotina, pois é o único caminho para sua própria sobrevivência.

6. Consultar: https://data.oecd.org/emp/hours-worked.htm. Acesso em: 17 de abril de 2020.

7. Banco Mundial. Afrodescendentes na América Latina: Rumo a um Marco de Inclusão. Washington, DC: World Bank, 2018.

8. UN-Habitat, World Cities Report 2016. Urbanization and Development: Emerging Futures (Ke Findings and Messages), Nairobi: United Nations Human Settlements Programme, 2016.

9. Consultar: https://heraldodemexico.com.mx/cdmx/llevan-campana-covid-19-a-lenguasindigenas-coronavirus-pueblos-ciudad-mexico-triqui-maya-mixteco/. Acesso em: 17 de abril de 2020.

10. Termo cunhado pelo camaronês Achile Mebembe (Necropolítica, São Paulo: n-1 edições, 2018).

11. Doutrina Monroe: proferida no dia 02/11/1823 pelo presidente James Monroe, a doutrina tinha como base a não intromissão europeia sobre quaisquer aspectos, principalmente devido ao passado de colonização; "américa para americanos".

\section{RESUMOS}

o conflito sensibiliza o cenário internacional, fazendo com que os atores tomem medidas para se proteger perante situações perigosas para o interesse nacional. A América Latina, em especial o Brasil e o México, vem falhado, no entanto, de proteger o seu maior tesouro: sua população. Em um mundo de incertezas, duas coisas são factuais: a balança de poder é fluída, e as marcas do passado histórico, social e econômico dos Estados brasileiro e mexicano, somado a uma má gestão do poder público se mostram, até hoje, ineficientes para sanar as necessidades de sua própria população.

El conflicto sensibiliza la escena internacional, haciendo que los actores tomen medidas para protegerse en situaciones que son peligrosas para el interés nacional. Sin embargo, América Latina, especialmente Brasil y México, no ha logrado proteger su mayor tesoro: su población. En un mundo de incertidumbres, dos cosas son objetivas: el equilibrio de poder es fluido, y las marcas del pasado histórico, social y económico de los Estados brasileño y mexicano, además de la mala gestión del poder público, siguen siendo ineficientes al atender las necesidades de su propia población.

The conflict sensitizes the international scenario, causing the actors to take measures to protect themselves in situations that are dangerous to the national interest. Latin America, especially Brazil and Mexico, has failed, however, to protect its greatest treasure: its own population. In a world of uncertainties, two things are factual: the balance of power is fluid, and the marks of the historical, social and economic past of the Brazilian and Mexican states, in addition to the poor management of public power, are still inefficient to address the needs of its own population. 
La scène internationale est sensibilisée contre le virus, en faisant que les acteurs se protègent face à des situations dangereuses par rapport l'intérêt nationale. L'Amérique Latine, notamment le Brésil et le Mexique, n'a pas réussi à préserver son trésor le plus précieux : sa population. Dans un monde d'incertitudes, deux choses sont cependant factuelles : la fluidité de la balance du pouvoir et l'héritage socio-économique des États brésilien et mexicain, ajoutées à une mauvaise gestion de la part du pouvoir publique, se révèlent insuffisants par rapport les besoins de la population en temps de crise pandémique.

\section{ÍNDICE}

Keywords: coronavirus, economic crisis, Latin America, Mexico.

Palabras claves: coronavirus, crisis económica, América Latina, México.

Mots-clés: crise pandémique, Amérique Latine, Mexique, Brésil, l'héritage socio-économique.

Palavras-chave: coronavírus, crise econômica, América Latina, México.

\section{AUTORES}

\section{ANA LUISA SENNA}

Discente do curso de Relações Internacionais da Universidade Federal Rural do Rio de Janeiro (UFRRJ), atualmente em intercâmbio como bolsista de Negocios Internacionales na Universidad Nacional Autónoma de México (UNAM). Estudante do Grupo de Pesquisa Reestruturação Econômico-Espacial Contemporânea, coordenado pelo Prof. Leandro Dias de Oliveira, desenvolvendo monografia de final de curso sobre logística e sustentabilidade. E-mails: anardsenna@gmail.com | analuisa.sennaa@gmail.com.

\section{KAREN LISSET BALTAZAR HERRERA}

Discente do curso deContabilidade da Universidad Nacional Autónoma de México. E-mail: kalizbaltazar@gmail.com.

\section{JHONATAN BENTO DA SILVA}

Discente do curso de Relações Internacionais da Universidade Federal Rural do Rio de Janeiro, atualmente em mobilidade internacional em Ciências Políticas na Universidad Autónoma de Tlaxcala (UATX - México). Bolsista do Programa Institucional de Bolsas de Iniciação Científica (PIBIC) do Conselho Nacional de Desenvolvimento Científico e Tecnológico (CNPq). E-mail: jhonatanbento.ri@gmail.com. 